\title{
Fostering Students' Participation In Online Environments: Focus On Interaction, Communication And Problem Solving
}

Nick Z. Zacharis, Technological Education Institute of Piraeus, Greece

\begin{abstract}
Rapid technological advances in the areas of telecommunications, computer technology and the Internet have made available to tutors and learners in the domain of online learning, a broad array of tools that provide the possibility to facilitate and enhance learning to higher levels of critical reflective thinking. Computer mediated communication tools such as email, threaded discussion lists, chat rooms, voice over IP, and whiteboards, can enhance online interaction and the development of critical thinking skills, giving learners a real chance to make their learning experience as close to a face-to-face situation. For this to happen, instructors have to adopt teaching strategies that create a successful student-centred learning environment in which students feel motivated and comfortable to participate and construct knowledge and meaning. This paper discusses the learning opportunities the online environment provides and the pedagogical changes that entails for quality learning, and focuses on instructional practices that fostering students' participation through appropriately designed interaction, effective communication and problem solving activities.
\end{abstract}

Keywords: online learning environments; quality learning; students' participation; interaction design; online discussions; problem solving activities.

\section{ONLINE ENVIRONMENTS AND LEARNING OPPORTUNITIES}

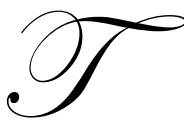

he movement from traditional face-to-face to online education has been gaining momentum. Taking advantage of current technology, instructors and institutions world-wide are discovering the potential of the online environment to deliver instruction of the highest quality to people who would otherwise have limited access to higher education. In the area of distance education, online learning refers to courses offered via the Internet and do not require participants to be in a specific place for most or all of the duration of the course. Online classes use web sites that provide a user friendly front end and easy access to text, graphics, audio and video materials that may be used in a common and consistent format. Usually they include basic course information such as syllabus, schedule, and announcements reading lists, and often integrate tools for synchronous or asynchronous communication, online testing, discussion groups, conferences, whiteboards, streaming audio and video. In online classes, students download electronic textbooks, audio and video files related to course content, send their tests to teachers' in-boxes, chat with peers and teachers online and communicate via e-mail, chat rooms and web conferences.

Online instruction provides a unique opportunity for learning materials, tasks and activities to fit individual learning styles and preferences. Online environments allow learners to take control over the learning process, engage in social interaction and dialogue, develop multiple modes of representation and become more self aware (Oliver and McLoughlin, 1999). As adult learners enrolling in online courses, the need for more inquiry activities and learner-centered approaches pushes instructors to create situations where students are building knowledge and sharing it with experts and peers who, in turn, offer authentic evaluation and timely feedback (Bonk, Wisher and Lee, 2004). 
There is a large and growing body of evidence that generally there is no significant difference between classroom instruction and online learning. This is mainly due to the fact that online learning at traditional institutions often is simply delivering the classroom course with the aid of technology. Most online materials are page turners and usually online courses are only calendars augmented with lecture notes. The real challenge for online instructors is to use technology to provide even higher quality instruction, combining subject content and pedagogical strategies to develop customized instruction for new student populations in learning environments where the needs of the students drive the curriculum and the instruction.

\section{NEW ROLES AND PEDAGOGIES FOR QUALITY ONLINE}

Boettclher (1999) defines online learning as an educational philosophy for designing interactive, responsive, and valid information and learning opportunities to be delivered at a time, place, and in appropriate forms convenient to the learners. Porter (1997) finds that the online environment, sometimes called the "virtual classroom," is not radically different from a traditional classroom and that any effective "classroom" includes six important elements: appropriate tools for learning are either provided or their location and access instructions are explained; there is an expectation of an environment conducive to learning; learners are brought together with educators to share information and exchange ideas; learners have opportunities to apply what they have learned and are free to experiment and make errors; there is a mechanism for evaluating performance; and the environment is safe for learning.

One of the major differences between traditional classroom instruction and online education is the amount of face-to-face contact students have with their teacher and with other students. Learning is a social process, and the support of teachers and classmates forms an important element of the learning that occurs. Although online learning environments provide the means for increased interaction, communication and collaboration, online students "often bring a range of expectations and backgrounds that have been set by the patterns of traditional classroom pedagogy: an active and present instructor; instructor directed activities and discussions; and a passive or merely responsive role for students" (Zapalska, 2004).

With a growing number of courses offered online, there is a considerable interest in concerns and problems associated with online education, particularly as it relates to the quality of online instruction. Traditional or face-toface instructional environments have been criticized because they encourage passive learning, ignore individual differences and needs of the learners, and do not pay attention to problem solving, critical thinking, or other higher order thinking skills (Hannum \& Briggs, 1982). For online education to be effective in addressing these issues, the online instructors must be flexible in constantly shifting between a number of roles such as lecturer, tutor, facilitator, mediator and co-learner.

Alley and Jansak (2001) have identified 10 keys to quality online learning. The authors suggested that online courses will be high quality when they are student-centered and when:

- $\quad$ Knowledge is constructed, not transmitted.

- $\quad$ Students can take full responsibility for their own learning.

- $\quad$ Students are motivated self-learners.

- $\quad$ The course provides opportunities for higher order learning and reflection.

- $\quad$ Learning activities take into consideration students' different learning styles.

- $\quad$ Engage students in active, experiential learning.

- $\quad$ Learning activities include individual and collaborative tasks.

- Inaccurate prior learning is identified and corrected.

- $\quad$ Spiral learning provides space and time for revision and expands prior lessons.

- $\quad$ The instructor is able to facilitate the overall learning process.

The online setting provides a level of flexibility and convenience not provided by traditional classroom courses. Effective teaching and learning in this setting requires responsible, motivated students whose aims are to learn and not to simply get passing grades. Many elements of an online environment can lead students to frustration, 
overloading, procrastination, passivity, isolation and finally disengagement. Instructors should not take for granted that students have the ability to use effectively the online component or have the required previous knowledge on the content subject or are willing to participate in meaningful discussions and knowledge shearing. In order for students to be motivated self-learners and learn on their own, instructors have to design an environment that promotes interaction, communication and problem solving, as means to encourage, motivate and engage students in the learning experience.

\section{DESIGNING INTERACTION IN ONLINE CLASSES}

Interaction is a key factor for students' satisfaction, motivation, retention and higher level of academic achievement. Chickering and Gamson (1987) suggested that the concept of interaction is a core element of the seven principles of good practice in education. These practices include: encouraging students / faculty contact; developing cooperation among students; engaging in active learning; providing quick feedback; emphasizing the amount of time dedicated to a task; communicating high expectations; and respecting diverse talents and ways of learning.

Moore (1989) described three classical forms of interaction in distance education: interaction between students and teachers, interaction between students, and the interaction of students with content. Hillman, Willis, and Gunawardena (1994) described another type of interaction, the learner-interface interaction, which focuses on the access, skills, and attitudes necessary for successful mediated interaction. Wagner (1994) defines interactions as "reciprocal events that require at least two objects and two actions. Interactions occur when these objects and events mutually influence one another. An instructional interaction is an event that takes place between a learner and the learner's environment. Its purpose is to respond to the learner in a way intended to change his or her behaviour toward an educational goal. Instructional interactions have two purposes: to change learners and to move them toward achieving their goals. "

The concept of interaction, as it applies to online learning, is more complicated than it has been treated in traditional classroom teaching, depending upon students personality, age or cognitive/learning styles, the type of media (real-time or asynchronous) used, the support and timely feedback, the sense of belonging in the learning community and students' perceptions of their learning experiences including "how well" or "how much" they have learned (Kearsley, 1995; Picciano, 2002). Since effective online instruction requires an active learner, a carefully designed course should involve interactions of all four types in order to promote control, feedback, participation, online presence, motivation and social exchange.

In learner-content interaction, the student interacts with the materials being studied. Current technologies provide a wide variety of media alternatives for creating content for student interaction: sound, text, graphics, video, and virtual reality. To be successful interacting with the selected media, students must have the skills to extract information and learn from the media. Instructor may enhance motivation through clarifying how learning the material will fulfil the student's needs, illustrating how the material is important, stating that the tests will be based on the material.

Learner-instructor interaction involves direct communication between the learner and the instructor through the use of email, discussion boards, online chats, instant messaging, voice over IP, and virtual classrooms (Bigus, 2004). In this process, the instructor assists students as they come to understand the course content and apply their knowledge, assesses students' comprehension or progress with the content, and offers the learner counselling, encouragement, and motivational support.

Learner - learner interaction, is defined as interaction between one learner and other learners, alone or in groups, with our without the real-time presence of the instructor. Team projects, debates, role playing, small-group discussions, requirements to post and respond to other postings on a discussion board, and chats used for discussion and brainstorming are all instructional components that can be used in online courseware to ensure learner-learner interaction (Bigus, 2004).

French et al (1999) argues that a) interactivity must be designed to support learning objectives, and b) the interface and infrastructure that support the content must be taken into account when designing interaction features. 
When instructors design online courses can not assume that learners know how to interact online and how to become more responsible for their online learning. The online component of the new environment may seem complicated and thus impose a cognitive load that makes students to spent mental resources in navigation and operational issues, causing them distress, disappointment and loss of interest. An initial class devoted in learning the use of the online component, with the presence of the instructor, will be beneficial for students. Padavano and Gould (2005) presented a useful set of interactions that encounters all these issues from the beginning of the course:

\section{Online Interactions Learner-Interface/Technology \\ - $\quad$ Provide an orientation to your online environment or content management tool \\ - $\quad$ Give detailed instructions to students about where things are located in the course, use links \\ - $\quad$ Give detailed instructions to students on how to submit assignments \\ - $\quad$ Provide a grade book and post feedback \\ - $\quad$ Provide a thread for students to ask questions about how to use the course management tool \\ - $\quad$ Provide a help desk for student questions}

\section{Online Interactions Learner-Content}

- $\quad$ Develop an interactive course road map

- Interactive syllabus with links and details

- $\quad$ Create a quiz about where to find content within course

- $\quad$ Set up a location with important content links

- $\quad$ Create question threads for weekly content questions

- Detail what is expected in multiple locations

- $\quad$ Create virtual labs for students to practice tasks

\section{Online Interactions Learner-Instructor}

- $\quad$ List contact information on the syllabus

- $\quad$ Set up communication guidelines and expectations

- $\quad$ Provide office hours in person or virtually using instant messenger tools or chat rooms

- $\quad$ Set up a weekly optional chat for students

- $\quad$ Provide prompt and detailed feedback on assessments and discussion responses

- $\quad$ Call students to clear up misunderstandings

- $\quad$ Make frequent announcements to the class

\section{Online Interactions Learner-Learner}

- $\quad$ Set up group or team projects within the course

- $\quad$ Create a thread for class members and instructor to make an introduction

- $\quad$ Create a weekly thread where students can ask each another questions

- $\quad$ Encourage group chats and email

- $\quad$ Set up guidelines for learner to learner communication and response expectations

- $\quad$ Set up a thread where the student facilitates the learning. "

Creating a safe climate for interaction and communication is an essential component to a successful online learning experience. Learners' anxiety and concern about the online learning environment has been shown to negatively impact online experiences. Early and often students should know that there are numerous supports available to assist them - including the orientation course, the help notes, the 24/7 help desk, and their peers and the instructor - and that it is okay to ask for help, to trust the instructor and the promise that he/she will be very available and accessible (Landon, 2004).

All popular learning management systems and many of the stand-alone assessment packages provides online instructors a variety of tools to create quizzes and surveys, set conditions for tests, set up an assignment submission area for students, collect student submissions, provide feedback and grades, and manage the grade book. In the same online environments, modules like My Files, My Grades and My Progress, give students personal space 
and control over their own learning. Online tests and quizzes, which may vary in terms of their principal purpose, question design and format, are opportunities for students to assess their knowledge, and they provide timely and diagnostic feedback on students' learning. A well-designed test or quiz helps students to check their knowledge and identify gaps and areas of misunderstanding, and gives tutors feedback on their progress and the opportunity to identify students at risk.

Procrastination is a major obstacle to effective time management, and often drives to increased stress, poor performance, and isolation. To help students avoid procrastination and participate actively in the designed activities, instructor must encourage them to be proactive in their learning by regularly logging into course site, submitting assignments and completing quizzes on time, reading messages posted and replying within required timeframe. Staying in personal contact with the students that seem to delay, instructor must always check that they understand an assignment and use properly the resources they need to successfully complete it. Advising students how to prioritize the tasks they are to do and helping them to focus on specific and more manageable parts of the assignment at hand, instructor helps students not to feel overwhelmed and take action rather than worry and procrastinate.

\section{COMMUNICATING EFFECTIVELY ONLINE}

A key to success of any online education program is a high level of communication. Palloff \& Pratt (2003), focusing on online student needs conclude that "what the virtual student wants and needs is very clear: communication and feedback, interactivity and a sense of community, and adequate direction and empowerment to carry out the tasks required for the course" (p. 129). Social interaction amongst the students in an online community can generate a feeling of trust and belonging, alleviate the sense of isolation and foster participation. A strong sense of online community can strengthen information exchange, learning support, commitment to group goals, collaboration, and satisfaction with group efforts (Palloff \& Pratt, 1999; Rovai, 2003). The discussion element of an online course plays a critical role in creating and sustaining this sense of community.

Online communication tools, from e-mail and discussion boards to chat, instant messaging and web conferencing, provide powerful platforms to set up discussions among students, implement collaborative assignments, foster peer tutoring and review, and encourage greater communication between students and instructors. Asynchronous discussions, allowing time for reflection by the learner, can produce greater depth of learning than the synchronous environment alone (Donaldson \& Conrad, 2004). The nature of threaded discussion "allows all voices to be heard because (a) students are usually required to respond and their participation can be easily documented and (b) those who may be intimidated by speaking in front of their peers or those who need more response time are more easily able to participate" (Black, 2005). Certain situations best lend themselves to synchronous communications. Such activities include group meetings or activities requiring group consensus or simultaneous response. Synchronous discussions are especially useful for brainstorming or replicating the face to face situation and tend to be more successful when utilized by small groups. While both synchronous and asynchronous discussions have advantages and disadvantages, their use together in a blended learning situation is critical to the development of the online learning community. Asynchronous, threaded discussions "complemented by the synchronous use of virtual white boards and chat rooms, allow student teams to collaborate on group projects, coupling real-time learning activities with opportunities to communicate at their convenience" (McCracken, 2002).

Teaching in any environment involves providing content and "leading the student to analyze, synthesize, and exercise critical judgments. These advanced skills require a high amount of interactivity between professor and student, as well as collaboration among students" (Weiss, 2000, p. 47). Interaction implies active learner participation in the learning process, through intense and effective communication with the members of the learning community. Since it should not be assumed that students know how to communicate or behave online, instructors need to have not only the technical competence but, more important, they need to understand the dynamics of online communication and interactions and use effective ways of moderating and facilitating online dialogs. Moderating involves: encouraging students to participate, ensuring that some students do not dominate, keeping discussion focused, bringing out multiple perspectives and summarizing highlights of the discussion. Facilitating involves: providing information to help students complete assignments, suggesting ideas or strategies to help students pursue course work, getting students to reflect on their response and work (Kearsley, 2000). 
Devoting some class time to the basic set up and procedures that will be used and defining rules for expected behaviour and tips for good use of online communication will prevent problems from occurring. Students need to know from the first day how their work, including informal and formal participation and contributions, will be judged. Clear guidelines, timelines and expectations for participation in discussions and team activities need to be developed and readily available. Individual and group objectives, roles and responsibilities should be defined clearly at the beginning to ensure maximum participation and contribution.

In order to provide a positive experience and ensure high levels of cognitive engagement and critical thinking in online discussions, the instructor must participate actively in them, setting meaningful and challenging but achievable tasks and providing timely feedback:

- $\quad$ Online discussions provide a perfect forum for an academic discourse which promotes increased student engagement, critical analysis and reflection, and the social construction of knowledge (Blumenfeld et al., 1996). Learners should be required to participate in online discussions and their grade should depend on participation. During the discussion instructors should be active in participation, answering queries, providing advanced content knowledge and insights, commenting on opinions and posing conflicting views to elicit more thinking.

- Tasks should be meaningful and relevant to the content and the goal of the instruction, and should invite students to built on prior knowledge and connect what they are learning to their everyday life. Students are more engaged in activities when they perceive that their "work is significant, valuable, and worthy of their efforts" (Policy Studies Associates, 1995). Students tend to give up easily on tasks that seem very difficult for them and seem to be less creative when they are engaged in tasks that are rote and repetitive.

- $\quad$ Clearly, the ideal is for instructors to give detailed personal feedback to each student. However, "when time constraints increase during the semester's busiest times, instructors can still give prompt feedback on discussion assignments by responding to the class as a whole instead of to each individual student. In this way, instructors can address patterns and trends in the discussion without being overwhelmed by the amount of feedback to be given" (Graham et al., 2001).

Rovai (2003) suggests grading online discussions provide extrinsic motivation for students to participate and interact, and he reports a significant increase in the number of student messages per week and a concurrent increase in sense of classroom community for courses in which discussions accounted for $10-20 \%$ of the course grade. Assessment of students' participation in online dialog can be based on several criteria, both quantitative and qualitative, such as: the frequency or length of postings-responses, the ability to pose new questions, identify problems, explain ideas and summarize in a coherent manner, the willingness to critically evaluate the work of others with constructive comments, and of course the quality of written speech.

The asynchronous threaded discussion environment gives tutors the opportunity to use a variety of different discussion formats and articulate meaningful learning activities facilitating critical thinking and engaging students. Basic discussion formats include:

- $\quad$ Buzz groups, consisting of two or three students who discuss to solve a simple problem or reach a common viewpoint on a topic within a specific period of time.

- Jigsaw discussion groups, where students form small teams to develop possible solutions to a problem from a specific point of view, and then present their findings to a different team.

- $\quad$ Role playing discussions, utilized by small groups create situations relating to real world problems in which participants act out various roles and defend specific positions.

- $\quad$ Case study discussions, where students using an authentic problem or experimenting with a simulation of a process or phenomenon, analyze data, use prior knowledge and investigate for solutions.

\section{LEARNING THROUGH PROBLEM SOLVING}

Engaging students in authentic, "real world" problems has been proven a unique instructional strategy for enhancing the content knowledge and the developing of higher cognitive abilities and collaborative skills (Jonassen, 2000; Hmelo-Silver \& Barrows, 2006). According to Jonassen, (2000, p. 63) "virtually everyone, in their everyday 
and professional lives, regularly solves problems", so "the central point of education is to teach people to think, to use their rational powers, to become better problem solvers" (Gagne, 1980, p. 85).

Problem-based learning (PBL) is an instructional method that challenges students to work cooperatively acquiring new knowledge and applying it to solve real world problems. PBL is a student-directed approach: requires students to become responsible for their own learning, promotes active learning and emphasizes critical thinking skills, understanding, learning how to learn and working cooperatively with others (Duch, Groth \& Allen, 2001).

Traditional education rarely requires students to solve problems encountered in the real world. In the most educational contexts, new concepts are presented in a lecture format and tested by "end-of-the-chapter" well structured problems. A well-structured problem yields a right answer through the application of an appropriate algorithm. Most textbook problem sets in mathematics, physics, engineering, or business feature well-structured problems. In PBL, problems are designed to be "ill-structured" and to imitate the complexity of everyday life. In contrast to the well structured problems, that have a definitive "correct" answer, ill structured problems may have more than one approach or answer because they are complex and ill-defined. The "best" solutions to ill-defined problems depend on the priorities underlying the situation. Assumptions and constraints are necessary in such problems because they set limits, reflect desired values and simplify the problem.

The principal idea behind problem-based solving is that the starting point for learning should be a problem, a query or a puzzle that the learner wishes to solve (Boud, 1985, p. 13), and not the provision of content via lecture and texts. Students are presented with a problem and they begin working in small groups and negotiate in defining the problem precisely, assess what they know, identify what they need to know, plan how to proceed, gather information, collaborate on the evaluation of hypotheses, brainstorm possible solutions, choose one solution, look back and reflect and arrive at clearly stated solutions. Collaborative exchanges in problem solving extend cognitive activity and team members are able to monitor individual thinking, cope with different opinions, give and take feedback that results in clarification and change, and provide social support and encouragement to each other (Alavi, 1994). When disagreement occurs between peers about how to break down a complex problem into smaller solvable problems, or how to test a proposed hypothesis or support an analogy to a similar problem that has been solved before, less knowledgeable members learn from the explanations of more advanced peers and progressively fill the gaps in prior knowledge and integrate new concepts in a more solid knowledge structure. As students find their ways through complex or new tasks, anxiety and uncertainty are reduced while self-confidence, motivation and participation are increased.

The online instructors should not expect students to be effective problem solvers right away. Creating a comfortable and safe online environment in which students are encouraged to question and discuss different ideas and approaches to solving problems, the instructor can use a variety of support mechanisms or "scaffolds" to provide content knowledge and feedback, on a just-in-time basis. Scaffolds "may take many forms including learner guides, resources, tools and strategies that help the learner overcome any lack of domain knowledge and attain higher levels of understanding" (Galea, Kelly \& Steel, 2007). As students become more experienced with PBL, instructors can fade their scaffolding until finally the learners adopt much of their inquiry style.

The PBL teacher is a facilitator of students' learning, guiding them to think deeply and collaborate effectively, and modelling the kinds of questions students needs to be asking themselves. Through discussions the teacher forms questions and presents worked examples or relevant simulations, modelling good strategies for learning and thinking, rather than providing expertise in specific content (Sweller, 2006; Hmelo-Silver \& Barrows, 2006):

- Scaffolding the content processing instructor intervenes in the discussions when is needed and uses questions to: probe the reasoning process, clarify misunderstandings, help students see connections, tie together information and draw conclusions, and keep the discussion on track. At the same time instructor monitors and influences the group dynamics engaging all students and supporting interpersonal relations (Allen \& White, 2001).

- Worked examples, that are annotated with the concept expressed in each line of the solution, can reduce the cognitive load associated with the use of problem solving search strategies and function better than simply providing hints based on fundamental concepts of the target domain (Ringenberg \& VanLehn, 2006; Sweller, 2006). Providing examples or models for students to follow, along with comments explaining why the 
examples are good, instructor communicates high expectations for students' performance (Graham et al., 2001).

- Using appropriately designed simulations, the instructor can create environments for active participation and engagement that can promote learning by including opportunities to solve problems and examine phenomena across contexts, providing authentic experiences that are too risky or expensive to otherwise implement (Stevens and Dexter, 2003).

An essential barrier to effective online participation in topic discussions and problem solving activities is the lack of prerequisite subject matter knowledge or preparation by the students. Online lecture materials or supplements including lists with key terms and concepts, examples, drill-and-practice activities or interactive web activities organized around a main topic, allow students to obtain a basic level of knowledge so that instructors can facilitate and enhance learning to higher levels of critical reflective thinking. Before any discussion about a certain topic or problem, online preparation quizzes can be used to test students' readiness and comprehension of needed concepts. Instructors' feedback can correct conceptual errors and give students an external motivation to participate effectively in group activities.

A major challenge that instructors must face when implementing a problem-based/ inquiry curriculum is deciding how to assess student learning. Assessment in PBL is required to direct student learning and to give staff feedback on the curriculum as much as it is to measure outcomes. Summative assessments based on objective questions that test the student's comprehension, should be complemented with formative assessments to provide regular, informative and detailed feedback to teachers and students over the course of instruction. Formative assessments may include group or individual presentations, case-based individual essays, self assessments and peer assessments. Giving students the opportunity to present their work and evaluate their own and their peers' achievements is a key element in PBL. Self and peer evaluation are valuable tools to help students become more confided and self-directed learners, encourage their accountability and responsibility, and motivate them to participate more substantially in the learning community.

\section{CONCLUSION}

Technology can help instructors to create an active online environment in which students take responsibility and control for their own learning, solve problems, build and share understanding in an interactive learning community. Barriers such as lack of prerequisite subject matter knowledge, lack of technical ability to use the online component and lack of willingness to participate in online discussions and collaborative activities, negatively impact online experiences. To remove these barriers and motivate students to participate actively in the learning process, online instructors can rely on carefully designed interactions, successful online discussions and collaborative problem solving activities:

- $\quad$ Designing interactions of all four types, providing time for students to practice and master the technologies needed to interact with one another, and sustaining an open, safe and comfortable environment in which questions can be asked, ideas tried, anxieties expressed, online instructor can motivate students for further engagement.

- Using a variety of discussion formats the instructor may be able to determine the most appropriate venues for communication with and between students. Giving and accepting feedback, and following the line of questioning and reasoning developed as discussion on topics progresses, students become more aware of the value of clarity and logical consistency and strive to contribute deeper and more reflective responses.

- $\quad$ Providing students with authentic problems and supporting them with probing questions, worked examples and real world simulations, instructor stimulates students' attention, brings existing knowledge into their consciousness and motivates them participate and apply what they have learnt.

\section{AUTHOR INFORMATION}

Nick Z. Zacharis is a Lecturer at the Computer Science Division of Department of Mathematics, Technological Institute of Piraeus and teaches undergraduate and postgraduate courses on Software and Web Development. In addition, he is a research scientist at the Knowledge Engineering Laboratory at the University of Piraeus. His research interests include Internet search engines, information filtering and collection, distance learning techniques. 


\section{REFERENCES}

1. Alavi, M. (1994). Computer-mediated collaborative learning: An empirical evaluation, MIS Quarterly 18, 2 (June 1994), 159-174.

2. Allen, D.E. and H.B. White, III. (2001). Undergraduate group facilitators to meet the challenges of multiple classroom groups. Chapter in, The Power of Problem-Based Learning: A Practical 'How To' for Teaching Undergraduate Courses in Any Discipline. B. J. Duch, S. E. Groh, and D. E. Allen, eds. Sterling, VA: Stylus Publications.

3. Alley, L. R. \& Jansak, K. E. (2001). The ten keys to quality assurance and assessment in Online Learning. Journal of Interactive Instruction Development, 13 (3), 3-18.

4. $\quad$ Bigus, J., 2004. Interactivity and Web-Based Courseware. Retrieved July 10, 2008, from http://www.bigusbooks.com/mastersportfolio/products/InteractivityAndWebBasedCourseware.pdf

5. Black, A. (2005). The use of asynchronous discussion: Creating a text of talk. Contemporary Issues in Technology and Teacher Education [Online serial], 5(1).

6. Blumenfeld, P.C., Marx, R.W., Soloway, E. \& Krajcik, J. (1996) Learning with Peers: From Small Group Cooperation to Collaborative Communities. Educational Researcher, 25, 8, 37-42.

7. Boettcher, J. (1999). Nuggets about: the shift to web-based teaching and learning. Florida State University.

8. Bonk, C., Wisher, R., Lee, Ji-Yeon., (2003). Moderating Learner-Centered E-Learning: Problems and Solutions, Benefits and Implications, in Online Collaborative Learning: Theory and Practice, T. S. Roberts, ed. (Hershey, Pa.: Idea Group Publishing, 2003), 54-85.

9. Boud, D. J. (1985). Problem-based learning in perspective. In D. J. Boud (Ed.), Problem-based learning in education for the professions. Sydney, Higher Education Research and Development Society of Australasia

10. Chickering, A. W., \& Gamson, Z. F. (1987). Seven principles for good practice in undergraduate education. AAHE Bulletin, 39(7), 3-6.

11. Conrad, R., \& Donaldson, J.A. (2004). Engaging the Online Learner: Activities and Resources for Creative Instruction. San Francisco, CA: Jossey-Bass.

12. Duch, B.J., Groh, S.E.and Allen, D.E.. (2001). The power of problem-based learning. Sterling, VA: Stylus.

13. French, D., Hale, C., Johnson, C., Farr, G., (1999. Internet based learning: an introduction and framework for higher education and business. Stylus Publishing, Sterling, Virginia.

14. Gagne, R. M. (1980). The conditions of learning. New York: Holt, Rinehart, \& Winston.

15. Galea, V., Kelly, G. \& Steel, C. (2007). The Virtual Plant Pathology Laboratory CD-ROM: an authentic learning environment designed to teach the principles of plant disease case management. Ascilite Newsletter, May 2007. http://www.ascilite.org.au

16. Graham, C., Cagiltay, K., Craner, J., Lim, B., \& Duffy, T. M. (2001). Seven Principles of Effective Teaching: A Practical Lens for Evaluating Online Courses. Technology Source March/April 2001. http://technologysource.org/article/seven_principles_of_effective_teaching/

17. Hannum, W., \& Briggs, L. (1982). How does instructional system design differ from traditional instruction? Educational Technology, 22(1), 9-14.

18. Hillman, D. C., Willis, D. J., \& Gunawardena, C. N. (1994). Learner-interface interaction in distance education: An extension of contemporary models and strategies for parishioners. The American Journal of Distance Education, 8(2), 30-42.

19. Hmelo-Silver, C.E. (2004). Problem-based learning: What and how do students learn? Educational Psychology Review, 16(3), 235-266.

20. Jonassen, D. H. (2006). On the role of concepts in learning and instructional design. Educational Technology Research and Development, 54(2), 177-196.

21. Kearsley, G. (1995). The nature and value of interaction in distance learning. In Distance Education Research Symposium 3: Instruction (83-92).

22. Kearsley, G., 2000. Online education: Learning and teaching in cyberspace. Wadsworth.

23. Landon, E. (2004). "High touch" in a "high tech" world: Strategies for individualizing online learning. Educator's Voice Feb 11.

24. McCracken, H. (2002). The importance of learning communities in motivating and retaining online learners. In V. Phillips, B. Elwert, L. Hitch, \& C. Yager (Eds.), Motivating and retaining adult learners online (. 65-74). Virtual University Gazette.

25. Moore, M. G. (1989). Three types of interaction. The American Journal of Distance Education, 3(2), 1-6. 
26. Oliver, R. \& McLoughlin, C. (1999). Curriculum and learning-resources issues arising from the use of web-based course support systems. International Journal of Educational Telecommunications, 5(4):419436.

27. Padavano, D., Gould, M. (2005). Student Satisfaction with Faculty-Student Interaction. Sloan-C International Conferences on Asynchronous Learning 2005.

28. Palloff, R. M., \& Pratt, K. (2001). Lessons from the cyberspace classroom: The realities of online teaching. San Francisco: Jossey-Bass.

29. Palloff, R. M, \& Pratt, K. (2003). Virtual student: A profile and guide to working with online learners. San Francisco, CA: Jossey-Bass.

30. Picciano, A.G. (2002) Beyond student perceptions: issues of interaction, presence, and performance in an online course. JALN, Volume 6, Issue 1, 21-40.

31. Policy Studies Associates (1995). Raising the educational achievement of secondary school students: An idea book. Volume 1, summary of promising practices. Washington, DC: U.S. Department of Education.

32. Porter, L. R. (1997). Creating the virtual classroom: Distance learning with the internet. New York: John Wiley \& Sons, Inc.

33. Ringenberg, M. and VanLehn, K.(2006). Scaffolding Problem Solving with Annotated Worked-Out Examples to Promote Deep Learning. ITS 2006, 625-634.

34. Rovai, A. P. (2003). Strategies for grading online discussions: Effects on discussions and classroom community in Internet-based university courses, Journal of Computing in Higher Education 15 (2003) (1), 89-107.

35. Stevens, R. and Dexter S., (2003). Developing teachers' decisions-making strategies for effective technology integration: A simulation design framework. Symposium presentation, AERA National Meeting, 2003.

36. Sweller, J. (2006). The worked example effect and human cognition. Learning and Instruction, 16, 165169.

37. Wagner, E. D. (1994). In support of a functional definition of interaction. The American Journal of Distance Education, 8(2), 6-29.

38. Weiss, R.E. (2000). Humanizing the online classroom. In R.E Weiss, D.S. Knowlton, \& B.W. Speck, (Eds.). New Directions for Teaching and Learning: Principles of Effective Teaching in the Online Classroom, (84), 47-52. San Francisco: Jossey-Bass Inc.

39. Zapalska, A., Bugaj, M., Flanegin, F., Rudd. D. (2004). Student Feedback on Distance Learning with the Use of WebCT. Computers in Higher Education Economics Review (CHEER), Volume 16, 2004. 